\title{
The Effect of Trade Openness on Carbon Dioxide Emission in Taiwan: A Quantile Mediation Analysis
}

\author{
TZU-KUANG HSU \\ Department of Business Administration \\ Chung Hua University \\ No.707, Sec.2 WuFu Rd., Hsinchu, \\ Taiwan, R.O.C.
}

Abstract: - This paper adopts an innovative method, called a quantile mediation analysis, which combines a quantile regression and mediation analysis to examine the impact of trade openness on carbon dioxide emission whether through economic growth or not from 1990 to 2018 in Taiwan. The result of the traditional ordinary least square approach shows that Taiwan's trade openness affects carbon dioxide emission through the full mediation effect of economic growth for the period of 1990-2018 and there is no direct relation between trade openness and carbon dioxide emission. Moreover, the results of this innovative analysis indicate that Taiwan's trade openness also affects carbon dioxide emission through the full mediation effect of economic growth at any distribution of carbon dioxide emission, and there is no direct effect from trade openness to carbon dioxide emission. This result indicates that trade openness only exists an indirect effect through economic growth in Taiwan. This finding supports Antweiler, Copeland and Taylor's point of view [1].

Key-Words: - a quantile approach, a quantile mediation analysis, carbon dioxide emission, economic growth, mediation analysis, trade openness

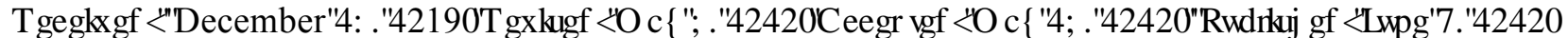

\section{Introduction}

For over four decades, trade openness has helped economic growth in both developing and developed countries. This growth, however, has come along with environmental consequences. According to Antweiler, Copeland and Taylor [1], trade openness can influence environment through the impact of trade on the level of economic activity such as more transportation services, and more production and consumption of goods and services, which results in environmental costs. This concludes that increased economic activity stimulated by trade openness worsens environmental quality. However, there has been a debate over the relationship between trade openness and environment since some studies found a positive relationship while others found a negative relationship. For example, some empirical studies showed that the trade openness leaded to environmental degradation, which came from individual countries differences in policy, economic structure, level of economic openness and countryspecific variables $[2,3,4,5,6,7]$. On the other hand, few empirical studies found trade openness improves environmental quality $[1,8,9]$. Moreover, Le, Chang, and Park [10] found that there exists the long-run relationship among trade openness, carbon dioxide emission, and economic growth for the global sample or for different income groups of countries. Even more, some empirical studies demonstrated that trade openness affects economic growth [11, 12, 13, 14]. Some empirical studies showed that economic growth caused carbon dioxide emission $[15,16,17,18,19,20]$. Especially, Grossman and Krueger [21] provided a systematic explanation for the relationship between gross domestic product (GDP) and environmental pollutants. They divide the economic development stage into three parts: scale effect, composition effect, and technique effect. The scale effect asserts that an increase in production impedes environmental quality; therefore, economic growth has a positive effect on environmental degradation. The composition and technique effect could decrease the detrimental effects of economic growth on environment quality.

The purpose of this paper is to investigate either if there is the direct relationship from trade openness to carbon dioxide emission in Taiwan, or there is the indirect relationship from trade openness to carbon dioxide emission through economic growth in Taiwan, or if there exist both an indirect and indirect relationship. Moreover, in this study we use an innovative methodology proposed by Hsu [22], which is totally different from the past research studies and called a quantile mediation analysis. This innovative method combines a quantile regression proposed Koenker and Bassett [23] and 
mediation analysis proposed by Baron and Kenny [24] to investigate the dynamic short-run causal impact of trade openness on carbon dioxide emission across different conditional carbon dioxide emission from 1990 to 2018 in Taiwan. The advantage of using this quantile regression is that a quantile regression will be more robust $[25,26]$ because it estimates the median and the full range of other conditions, rather than ordinary least squares (OLS) regression to estimate mean.

This paper is organized as follows. In section II shows the methodology. Section III reports data collection, scope, and empirical results. Section IV provides the conclusions and further research.

\section{Methodology}

\subsection{A Quantile Regression}

A quantile regression is a statistical technique that can be used to estimate and conduct inference about conditional quantile function. Koenker and Bassett [24] suggested the quantile regression approach as an alternative to least squares regression in a wide range of applications. This approach not only takes into consideration the skewness of the distribution, but gives a more complete picture of the performance that is affected by the various independent variables. This technique was further developed by Koenker and Hallock [25] and Koenker [26].

Based on Koenker [26] paper, when an estimate of the various quantile of a population is desired, a quantile regression is used. By using a quantile regression, one of the advantages is that a quantile regression will be more robust in response to large outliers because it estimates the median and the full range of other conditions, rather than ordinary least squares regression to estimate mean. The quantile regression objective function, similar to the least absolute deviations, is a weighted sum of absolute deviations which gives a robust measure of location, so that the estimated coefficient vector is not sensitive to outlier observations on the dependent variable. Moreover, a quantile regression also provides a more efficient approach than the least square method when the error term is nonnormal. A quantile regression can be seen as a natural analogue in regression analysis to the practice of using different measures of central tendency and statistical dispersion to obtain a more comprehensive and robust analysis. Lastly, the advantage of a quantile regression is that any quantile can be estimated when we have enough data. According to Koenker and Bassett [23, 25, 26] method, we first let $\mathrm{y}_{\mathrm{t}} \mathrm{t}=1,2, \ldots, \mathrm{T}$ be a random sample on the following regression process.

$$
y_{t}=x_{t} \beta+u_{t}
$$

Equation 1 has a conditional distribution function as equation 2 showed.

$F_{Y / X}(y)_{=} F\left(Y_{t} \leq y\right)=F\left(y_{t}-x_{t} \beta\right)$

where $\mathrm{x}_{\mathrm{t}}, \mathrm{t}=1,2, \ldots, \mathrm{T}$ denote a sequence of (row) $\mathrm{k}$ vectors of a known design matrix. The $\theta^{\text {th }}$ regression quantile, $\mathrm{Q}_{\mathrm{y} / \mathrm{x}}(\theta), 0<\theta<1$ is defined as any solution to the following minimization problem

$$
\begin{aligned}
& \min _{\beta}\left[\theta \sum\left|y_{t}-x_{t} \beta\right|+(1-\theta) \sum\left|y_{t}-x_{t} \beta\right|\right] \\
& \left\{t: Y_{t} \geq X_{t} \beta\right\} \quad\left\{t: Y_{t}<X_{t} \beta\right\}
\end{aligned}
$$

The resulting solution to equation 3 is denoted $\operatorname{as} \beta_{\theta}$, from which we obtain the $\theta^{\text {th }}$ conditional quantile $\mathrm{Q}_{\mathrm{y} / \mathrm{x}}(\theta)=\mathrm{x} \boldsymbol{\beta}_{\theta}$

\subsection{Meditation Analysis on Economic Growth}

We can use mediation analysis to investigate the causality from trade openness to carbon dioxide emission through economic growth and the direct relation between trade openness and carbon dioxide emission in equations 4 to 6 . The most common approach to examine mediation effect is the causal steps proposed by Baron and Kenny [24]. This analysis involves the following set of regression equations relating the independent variable, mediator variable, and dependent variable:

$$
\begin{aligned}
& \mathrm{CO} 2=\mathrm{b}_{0}+\mathrm{b}_{1} \text { OPEN }+\mathrm{e}_{1} \\
& \text { GROW }=\mathrm{c}_{0}+\mathrm{c}_{1} \text { OPEN }+\mathrm{e}_{2} \\
& \mathrm{CO} 2=\mathrm{d}_{0}+\mathrm{d}_{1} \text { OPEN }+\mathrm{d}_{2} \text { GROW }+\mathrm{e}_{3}
\end{aligned}
$$

Here, the degree of trade openness (OPEN) is measured as the rate of imports in relation to GDP and $\mathrm{CO} 2$ is per capita carbon dioxide emission in metric tons. Economic growth (GROW) is measured as the real Gross Domestic Product. Technically, $e_{i}$, $\mathrm{i}=1,2,3$ is the stochastic error term. Meditation analysis on economic growth processes are as following:

Step 1: The independent variable OPEN need to relate to the dependent variable $\mathrm{CO} 2$, such that $b_{1}$ in Equation 4 is significant. This condition is used to establish that there is a direct relationship between OPEN and $\mathrm{CO} 2$ to be mediated.

Step 2: The independent variable OPEN need to relate to the mediator variable GROW, such that $\mathrm{c}_{1}$ 
in Equation 5 is significant. This condition establishes the first stage of the mediated effect.

Step 3: The mediator variable GROW should relate to the dependent variable $\mathrm{CO} 2$, such that $\mathrm{d}_{2}$ in Equation 6 is significant. This condition establishes the second stage of the mediated effect.

Step 4: The independent variable OPEN should no longer relate to the dependent variable $\mathrm{CO} 2$ after the mediator variable GROW is controlled, such that $\mathrm{d}_{1}$ in Equation 6 is not significant. This condition shows that the relationship between OPEN and $\mathrm{CO} 2$ examined under the first condition disappears when the mediated effect transmitted through GROW is taken into account.

Satisfying all four steps provides evidence for complete mediation, whereas satisfying the first three steps indicates partial mediation if $d_{1}$ in Equation 6 is still significant and is smaller than $b_{1}$ in Equation 4.

\subsection{A quantile meditation analysis}

An innovative method, proposed by Hsu [1], combines a meditation analysis and quantile regression which substitute equation 3 into equations 4 to 6 , can be described to equations 7 to 9. This analysis provides a useful supplement to the standard constant-parameter regression estimate (only one $\mathrm{b}$ or $\mathrm{c}$ or $\mathrm{d}$ ) for studying all possible parameters (for all quantiles) vary across high dependent variable and low dependent variable. This novel method also leads to a more dynamic and complete understanding of what might really lie behind the stories of great effect or non-effect for trade openness on carbon dioxide emission. The quantile regression minimizes a weighted sum of the positive and negative error terms in equations 7 to 9 .

$$
\begin{aligned}
& \begin{array}{l}
\min _{b} \theta \sum \\
(1-\theta) \sum \mid \mathrm{CO} 2_{\mathrm{t}}-b_{0}-b_{1} \text { OPEN }_{\mathrm{t}} \\
\mathrm{CO} 2_{\mathrm{t}}-b_{0}-b_{1} \text { OPEN }_{\mathrm{t}}
\end{array} \mid+ \\
& \min _{c} \theta \Sigma \mid \text { GROW }_{\mathrm{t}}-c_{0}-c_{1} \mathrm{OPEN}_{\mathrm{t}} \mid+ \\
& (1-\theta) \sum \mid \text { GROW }_{\mathrm{t}}-c_{0}-c_{1} \text { OPEN }_{\mathrm{t}} \mid \\
& \min _{d} \theta \Sigma \mid \mathrm{CO}_{\mathrm{t}}-d_{0}-d_{1} \text { OPEN }-d_{2} \text { GROW } \mid+ \\
& (1-\theta) \Sigma \mid \mathrm{CO}_{\mathbf{t}}-d_{0}-d_{1} \mathrm{OPEN}_{\mathbf{t}}-d_{2} \text { GROW }
\end{aligned}
$$

\section{Results}

This study uses annual Taiwan data that covers the period 1990-2018. The data on carbon dioxide emission (CO2) are from Bureau of Energy, Ministry of Economic Affairs in Taiwan. The variables of openness (OPEN) and economic growth (GROW) are compiled from the Taiwan Economic Journal. All variables are in logarithmic form except the openness variable.

Before estimating equations 7 to 9 , we use the Augmented Dickey-Fuller (ADF) unit root test to examine the null hypothesis that a unit root is present in a time series and to determine the order of integration of these three variables. Table 1 display the unit root test results in levels and first differences with trend and intercept. The results show that we cannot reject the null hypothesis of the unit root for three variables in levels because $p$ value is greater than 0.05 . However, we reject the null hypothesis of a unit root at the $1 \%$ significant level or better for the first- value difference of these three variables since $\mathrm{p}$ value is smaller than 0.01 . Based on the results from the ADF test, these three data series integrated of order one.

Table 1 Results from the Augmented Dickey-Fuller Unit Root Test

Variable Level $p$-value 1st difference $p$-value

\begin{tabular}{lllll}
\hline GROW & -1.928 & 0.613 & -5.297 & $0.001^{*}$ \\
OPEN & -2.282 & 0.429 & -6.610 & $0.000^{*}$ \\
CO2 & -1.398 & 0.839 & -4.519 & $0.006^{*}$
\end{tabular}

* Denotes significance at the $1 \%$ level.

Regarding the causal relationship between trade openness and carbon dioxide emission, and trade openness and economic growth in equations 7 and 8 , we demonstrate the causality test results in Table 2. The notation of $x \neq>y$ means that the variable $x$ does not affect the variable $y$.

We find out some remarkable results as follows. First, there is the causal relationship from trade openness to carbon dioxide emission by using traditional ordinary least square method (OLS). Second, by using a quantile approach, there also exists causality running from trade openness to carbon dioxide emission at distributions (0.1 to 0.6 ) of carbon dioxide emission, but no causal relationship at higher distributions (0.8) of carbon dioxide emission. In other word, there is no direct relationship between trade openness and carbon dioxide emission at higher distributions of carbon dioxide emission. Lastly, there exists causality 
running from trade openness to economic growth by using traditional OLS method and at any distributions of carbon dioxide emission in Table 2. This result establishes the first stage of the mediated effect. It asserts that we only consider the mediated effect at below 0.6 distributions of carbon dioxide emission.

Table 2 Results from OPEN to $\mathrm{CO} 2$ and from OPEN to GROW at Different Quantiles

\begin{tabular}{ccccc}
\hline Quantile & \multicolumn{3}{c}{ OPEN $\neq$ CO2 } & OPEN $\neq>$ GROW \\
& $b_{1}$ & $p$-value & $c_{1}$ & $p$-value \\
& & & & \\
\hline 0.20 & $0.843^{*}$ & 0.001 & $0.834^{*}$ & 0.000 \\
0.40 & $0.802^{*}$ & 0.000 & $0.732^{*}$ & 0.000 \\
0.50 & $0.734^{*}$ & 0.001 & $0.787^{*}$ & 0.000 \\
0.60 & $0.593^{*}$ & 0.017 & $0.760^{*}$ & 0.000 \\
0.80 & 0.297 & 0.310 & $0.820^{*}$ & 0.030 \\
OLS & $0.799^{*}$ & 0.000 & $0.810^{*}$ & 0.000
\end{tabular}

*Denotes significance at the $5 \%$.

The table 3 shows that $d_{2}$ is significant both by using traditional OLS and a quantile approach at lower distribution of carbon dioxide emission in Equation 9, that is, the mediator variable GROW relates to the dependent variable $\mathrm{CO} 2$. This result establishes the second stage of the mediated effect.

Moreover, through the OLS method, the variable OPEN should no longer relate to the dependent variable $\mathrm{CO} 2$ after the mediator variable GROW is controlled, such that $d_{1}$ is not significant in Equation 9. This condition shows that the relationship between OPEN and $\mathrm{CO} 2$ examined under the first condition disappears when the mediated effect transmitted through GROW is taken into account. This result evidences the complete mediation because of satisfying all four steps in equations 4 to 6.

Third, through a quantile mediation analysis, the variable OPEN also no longer relate to the dependent variable $\mathrm{CO} 2$ after the mediator variable GROW is controlled at all distributions of carbon dioxide emission in table 3. This condition shows that the relationship between OPEN and $\mathrm{CO} 2$ examined under the first condition disappears when the mediated effect transmitted through GROW is taken into account. This result evidences the complete mediation because of satisfying all four steps in equations 4 to 6 .

The results of the effects of trade openness on carbon dioxide emission are different from the previous results. Appling traditional ordinal least square method, we find trade openness affects carbon dioxide emission through the full mediation effect of economic growth for the period of 19902018 and there is no direct relation between trade openness and carbon dioxide emission, which is totally different from the previous empirical findings. Moreover, by using a quantile regression and mediation analysis, we find trade openness affects carbon dioxide emission through the full mediation effect of economic growth at below 0.6 distributions of carbon dioxide emission. However, at above 0.6 distributions of carbon dioxide emission, there is no direct and indirect (mediation) effects from trade openness to carbon dioxide emission in Taiwan.

Table 3 Results from OPEN and GROW to CO2 at Different Quantiles

\begin{tabular}{lrlll} 
Quantile & \multicolumn{3}{c}{ OPEN $\neq>\mathrm{CO} 2$} & \multicolumn{2}{c}{ GROW $\neq>\mathrm{CO} 2$} \\
& $d_{1} \quad p$-value & $\mathrm{d}_{2}$ & $p$-value \\
& & & & \\
\hline 0.20 & 0.055 & 0.685 & $0.922^{*}$ & 0.000 \\
0.40 & 0.106 & 0.463 & $0.855^{*}$ & 0.000 \\
0.50 & 0.116 & 0.428 & $0.819^{*}$ & 0.000 \\
0.60 & 0.088 & 0.535 & $0.856^{*}$ & 0.000 \\
0.80 & -0.100 & 0.778 & $1.198^{*}$ & 0.031 \\
OLS & 0.068 & 0.485 & $0.903^{*}$ & 0.000
\end{tabular}

*Denotes significance at the $5 \%$.

\section{Conclusion}

Several empirical literatures have examined the causal relationship from trade openness to carbon dioxide emission. Most research results found a directly positive effect of trade openness on carbon dioxide emission by using the ordinary least square method. However, in this paper we not only investigate if there is the direct relationship from trade openness to carbon dioxide emission in Taiwan, but also if there is the indirect relationship from trade openness to carbon dioxide emission through economic growth in Taiwan. Moreover, in this study we use an innovative methodology which combines mediation analysis and a quantile regression that has allowed to obtain the full characterization of the conditional distribution of the dependent variable (carbon dioxide emission in our study), rather than its conditional mean only. That is, we provide a comprehensive picture of trade openness to carbon dioxide emission in Taiwan over the period of 1990 to 2018 . The result of the 
traditional ordinary least square approach shows that Taiwan's trade openness affects carbon dioxide emission through the full mediation effect of economic growth for the period of 1990-2018 and there is no direct relation between trade openness and carbon dioxide emission. Furthermore, the results of this innovative analysis demonstrate that Taiwan's trade openness also affects carbon dioxide emission through the full mediation effect of economic growth at below 0.6 distributions of carbon dioxide emission, but at above 0.6 distributions of carbon dioxide emission, there is no directly and indirect effect from trade openness to carbon dioxide emission. This result indicates that trade openness either only exists an indirectly effect through economic growth or no direct and indirect effect on carbon dioxide emission in Taiwan. Because we only use Taiwan data to examine the effect of trade openness on carbon dioxide emission and other factors which affect the carbon dioxide emission are not examined in this study. Therefore, we could use this method to further analyze other countries and other factors in the future research.

\section{References:}

[1] Antweiler, W., Copeland, R.B., and Taylor, M.S., Is Free Trade Good for the Environment? American Economic Review, Vol.91, No.4, 2001, pp. 877-908.

[2] Baek, J., Cho, Y., and Koo, W.W., The Environmental Consequences of Globalization: a Country Specific Time-Series Analysis. Ecological Economics, Vol. 68, 2009, pp. 2255-2264.

[3] Boulatoff, C., and Jenkins, M., Long-Term Nexus Between Openness, Income and Environmental Quality. International Advances in Economic Research,. Vol.16, 2010, pp. 410418.

[4] Naranpanawa, A., Does Trade Openness Promote Carbon Emissions? Empirical evidence from Sri Lanka. Empirical Econnmics Letters, Vol. 10, 2011, pp. 973-986.

[5] Wiebe, K.S., Bruckner, M., Giljum, S., and Lutz, C., Calculating Energy-Related $\mathrm{CO} 2$ Emissions Embodied in International Trade Using a Global Input-Output Model. Economic Systems Research, Vol. 24 No.2, 2012, pp. 113-139.

[6] Forslid, R., and Okubo, T., Which Firms Are Left in The Periphery? Spatial Sorting of Heterogeneous Firms With Scale Economies in Transportation. Journal of Regional Science, Vol. 55, 2014, pp. 51-65.
[7] Managi, S., and Kumar, S., Trade-Induced Technological Change: Analyzing Economic and Environmental Outcomes. Economic Modelling, Vol. 26, 2009, pp.721-732.

[8] Cole, .A., and Elliot, R.J.R., Determining the Trade Environment Composition Effect: the Role of Capital, Labor and Environmental Regulations. Journal of Environmental Economic Management, Vol.46, 2003, pp. 363-383.

[9] Frankel, J., and Rose, A., Is Trade Good or Bad for the Environment? Sorting Out the Causality. Review of Economics and Statistics, Vol.87 No.1, 2005, pp. 85-91.

[10] Le, T.H., Chang, Y.H., and Park, D.H., Trade Openness and Environmental Quality: International Evidence. Energy Policy, Vol. 92, 2006, pp. 45-55.

[11] Harrison, A., Openness and Growth: a TimeSeries, Cross-Country Analysis for Developing Countries. Journal of Development Economics, Vol. 48, 1996, pp. 419-447.

[12] Jin, J.C., Openness and Growth in North Korea: Evidence From Time-Series Data. Review of International Economics, Vol. 11 No. 1, 2003, pp. 18-27.

[13] Brueckner, M., and Lederman, D., Trade Openness and Economic Growth: Panel Data vidence from Sub-Saharan Africa. Economica, Vol. 82, 2015, pp. 1302-1323.

[14] Mendali, G., The Impact of Trade Openness on Economic Growth in SAARC Countries: A Panel Data Analysis. Journal of International Economics, Vol. 10 No.1, 2019, pp. 3-10

[15] Lotfalipour, M.R., Falahi, M.A., and Ashena, M., Economic Growth, $\mathrm{CO} 2$ Emissions, and Fossil Fuels Consumption in Iran. Energy, Vol. 35, 2010, pp. 5115-5120.

[16] Chandran, V.G.R., and Tang, C.F., The Impacts of Transportation Energy Consumption, Foreign Direct Investment and $\mathrm{CO} 2$ Emissions in ASEAN-5 Economies. Renewable and Sustainable Energy Reviews, Vol. 24, 2013, pp. 445-453.

[17] Yin, J., Zheng, M., and Chen, J., The Effects of Environmental Regulation and Technical Progress on $\mathrm{CO} 2$ Kuznets Curve: an Evidence From China. Energy Policy, Vol. 77, 2015, pp. 97-108.

[18] Dogan, E., and Turkekul, B., CO2 Emissions, Real Output, Energy Consumption, Trade, Urbanization and Financial Development: Testing the EKC Hypothesis for the USA. Environmental Science and Pollution Research, Vol. 23, 2016. pp. 1203-1213. 
[19] Zoundi, Z., CO2 Emissions, Renewable Energy, and the Environmental Kuznets Curve: a Panel CO-integration Approach. Renewable and Sustainable Energy Reviews, Vol. 72, 2017, pp. 1067-1075.

[20] Alshehry, A.S., and Belloumi, M., Study of the Kuznets Curve for Transport Carbon Dioxide Emissions in Saudi Arabia. Renewable and Sustainable Energy Reviews, Vol. 75, 2017, pp. 1339-1347.

[21] Grossman, G.M., and Krueger, A.B., Environmental Impacts of a North American Free Trade Agreement. NBER Working Paper. Vol. 3914, 1991.

[22] Hsu, T.K., Exploring the Impact of Openness on Inflation in Taiwan: Mediation Analysis With A Quantile Approach. WSEAS Transactions on Business and Economics, Vol.17, 2020, pp. 133-139,

[23] Koenker, R., and Bassett, G., Regression Quantile, Econometrica, Vol. 46, 1978, pp3349.

[24] Baron, R.M., and Kenny, D.A., The ModeratorMediator Variable Distinction in Social Psychological Research: Conceptual, Strategic, and Statistical Considerations. Journal of Personality and Social Psychology, Vol. 51 No. 6, 1986, pp. 1173-1182.

[25] Koenker, R., and Hallock, K., Quantile regression, The Journal of Economic Perspectives, Vol.15, 2001, pp.143-156.

[26] Koenker, R., Quantile Regression, Econometric Society Monograph Series, Cambridge University Press, 2005. 